\title{
Expressional Alterations of Versican, Hyaluronan and Microfibril Associated Proteins in the Cancer Microenvironment
}

\author{
Hiroko Kuwabara, Masahiko Yoneda and Zenzo Isogai
}

Additional information is available at the end of the chapter

http://dx.doi.org/10.5772/55067

\section{Introduction}

The extracellular matrix (ECM) is composed of fibronectin, collagen, elastic fibers and microfibrils with many associated adaptor proteins and proteoglycans. The microenvironments of cancer tissues differ from those of normal tissues, and intimately communicate with the cancer cell surface. For example, in breast cancer stroma compared with a normal breast lobule, 2,338 genes are upregulated and 1,234 genes are downregulated in ductal carcinoma in situ, and a further 76 genes are upregulated and 229 genes are downregulated in invasive carcinoma [1]. Histologically, smooth muscle actin-positive fibroblasts appear in the cancer stroma. Cancer cells and their microenvironments seem to influence each other during early carcinogenesis, and the microenvironments appear to play important roles in cancer development. The tumor microenvironment is unique in containing higher amounts of versican and hyaluronan, and lower amounts of latent transforming growth factor $\beta$-binding proteins. These stromal changes in hyaluronanbinding proteins and microfibril-associated molecules may facilitate cancer spreading, and targeting of specific components of the cancer stroma could lead to effective anticancer therapies. In this chapter, we review the dynamics of ECM proteins such as versican, hyaluronan, fibrillin- 1 and latent transforming growth factor $\beta$-binding proteins in cancer tissues. In addition, hyaluronan-binding proteins are discussed.

\section{Versican}

Versican is a type of ECM proteoglycan that was initially identified in cultured human fibroblasts, followed by isolation of its chicken homolog, PG-M, from chondrogenic condensation areas of developing limb buds [2]. Versican is a macromolecule composed of a 
specific core protein and covalently linked glycosaminoglycan chains named chondroitin sulfate (CS), which are linear, negatively charged polysaccharides comprising repeating disaccharides of acetylated hexosamines [2,3]. It is produced by cancer, lymphoma and leukemia cells, as well as activated peritumoral fibroblasts. Imunohistochemical staining with an anti-versican antibody (clone; 2B1 [4]) showed that versican is accumulated in the stroma of cancers such as melanoma, breast cancer and ovarian cancer (Figure 1). Versican regulates cell adhesion, proliferation, migration, survival, differentiation and angiogenesis, and its expression is increased with higher tumor grade and worse outcome [3].

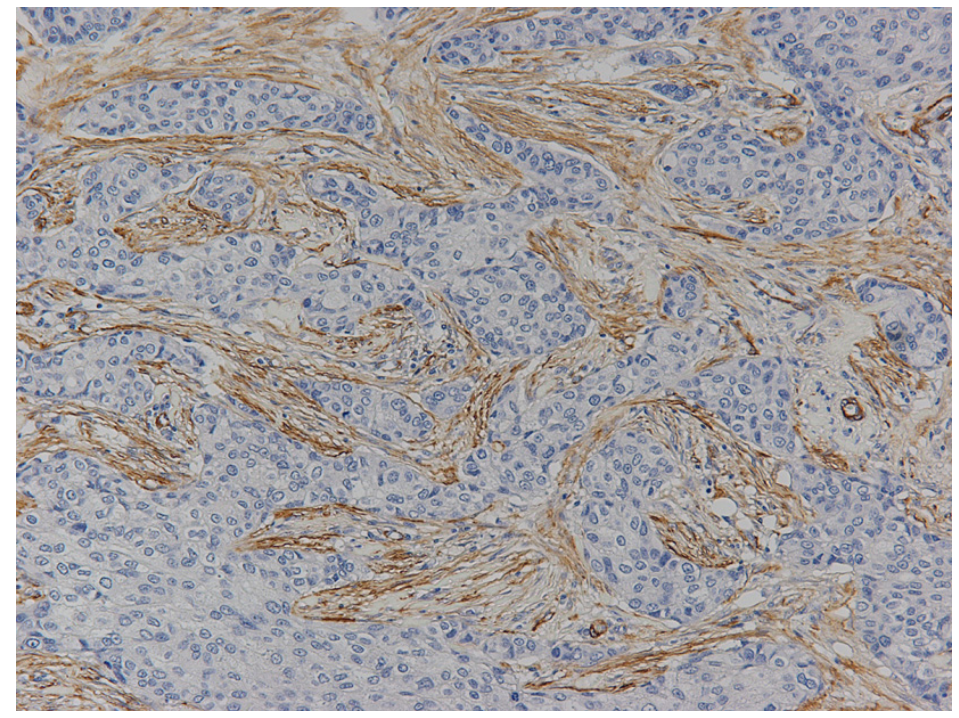

Figure 1. Anti-versican (2B1) immunohistochemistry of human invasive breast cancer. Versican is expressed in cancer stroma (x200).

Versican can be expressed as one of four splice variants (Figure 2) [5]. The amino- and carboxy-terminal globular domains (G1 and G3, respectively) are present in all isoforms, which differ in whether they contain two alternatively spliced CS-attachment regions (CS- $\alpha$ and CS- $\beta$ ). Specifically, versican V1 contains only the CS- $\beta$ region, V2 contains only the CS- $\alpha$ region, V0 contains both CS regions and V3 contains neither of the CS regions. Each versican isoform has different functional roles. The V1 isoform enhances cell proliferation and protects NIH3T3 mouse fibroblasts against apoptosis [6]. We investigated the alterations in versican isoforms in breast cancer tissues in comparison with matched normal tissues using real-time reverse transcriptase-polymerase chain reaction (RT-PCR) [7]. Total RNA was isolated using an SV total RNA isolation system (Promega, Madison, WI). First-strand cDNA was synthesized from the total RNA using a SuperScript VILO cDNA Synthesis Kit (Invitrogen, Carlsbad, CA), and amplified using specific primers for versican V0, V1, V2 and V3. The housekeeping gene glyceraldhyde-3-phosphate dehydrogenase (GAPDH) was amplified as an internal control. The designed primers were as follows: V0, 5'-gcacaaaatttcaccetgacatt-3' and 5'-cttctttagattctgaatctattggatgac-3'; V1, 5'- 
cccagtgtggaggtggtctac- $3^{\prime} \quad$ and $\quad 5^{\prime}$-ctcaaatcactcattcgacgtt-3'; V2, $3^{\prime}$ tcagagaaaataagacaggacctgatc-3', and 5'-catacgtaggaagtttcagtaggataaca-3'; and V3, 5'ccctcccctgatagcagat-3' and 5'-ggcacgggttcattttgc-3'. Real-time quantitative RT-PCR was performed using a Thermal Cycler Dice Real Time System (Takara Biochemicals, Shiga, Japan). Each PCR mixture contained $12.5 \mu$ l of Master Mix (SYBR Premix ExTaq ${ }^{\text {TMII; Takara }}$ Biochemicals), $0.01 \mathrm{~mol} / \mathrm{l}$ forward and reverse primers, and $100 \mathrm{ng}$ of first-strand cDNA in deionized water. After heating each sample to $95^{\circ} \mathrm{C}$ for $10 \mathrm{~s}, 45$ cycles of $95^{\circ} \mathrm{C}$ for $5 \mathrm{~s}$ and 60 ${ }^{\circ} \mathrm{C}$ for $30 \mathrm{~s}$ were performed. The fluorescence was measured as a function of temperature. All samples were run in triplicate, and PCR amplifications of the GAPDH and target genes were run in parallel for each sample. The results were analyzed by the Thermal Cycler Dice Real Time System TP800 software, version 2.00. To obtain estimates of the mRNA expression levels of the target genes by real-time RT-PCR, the GAPDH mRNA expression level was given a value of 1.0 and used to normalize the other mRNA expression levels. The cancer and normal tissues expressed all four versican isoforms, with the V1 isoform showing the most abundant expression in both tissues $(0.18 \pm 0.14$ in cancer tissues and $0.032 \pm 0.028$ in normal tissues) [7]. In the cancer tissues, the mRNA levels of V0 and V1 were increased by about 12fold and 6-fold, respectively, compared with the normal tissues. The mRNA levels of V2 and V3 were very low in the normal tissues, and did not change in the cancer tissues. The versican V1-transfected Swarm rat chondrosarcoma cells show enhanced cell motility and migration, and produce tumors with more spindle-shaped cells and more myxomatous stroma in SD rats [8]. These findings suggest that versican V1 enhances the invasive capacity and leads to the formation of a cell-associated matrix in the cancer tissues. V2 has the opposite functions to V1, by inhibiting cell proliferation and lacking any association with apoptotic resistance, whereas V3 expression has a dual role in tumor growth and metastasis [9,10].

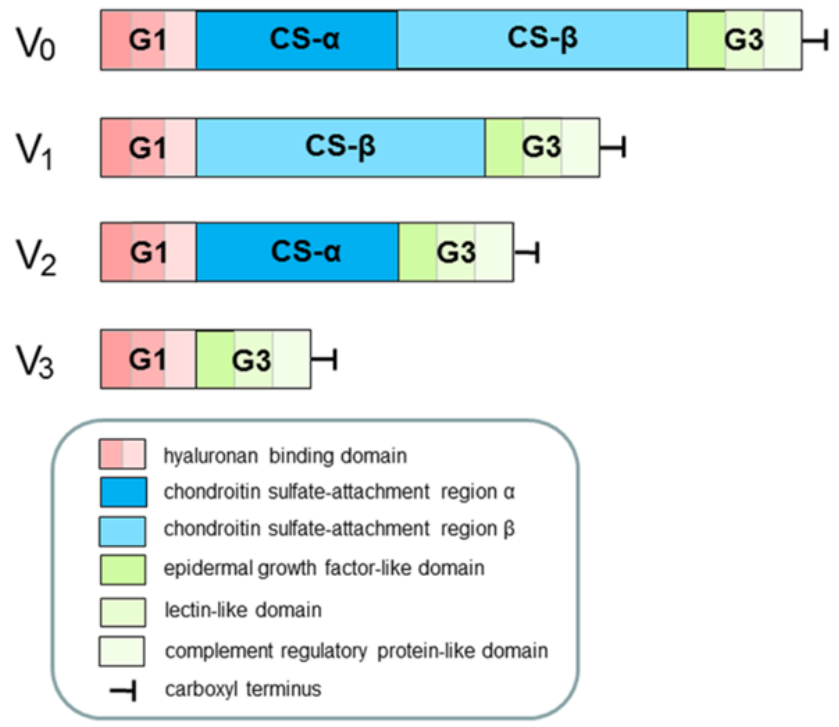

Figure 2. Schematic representation of human versican isoforms and domains. 
Globular domains G1 and G3 include a hyaluronan binding portion and epidermis growth like repeats, respectively, and they play a crucial role in the function of versican [2,3]. For these reasons, G1 and G3 in breast cancer and non-cancerous lesions were compared by dot blot analyses [7]. Frozen samples $(200 \mathrm{mg})$ were minced into small pieces using a Tissue Grinder System (Biomedical Polymers, Gardener, MA), homogenized in chilled lysis buffer comprising $4 \mathrm{M}$ guanidine- $\mathrm{HCl}$ and $1 \%$ protease inhibitor cocktail (Sigma, St. Louis, $\mathrm{MO}$ ), and extracted at $4^{\circ} \mathrm{C}$ for $48 \mathrm{~h}$. After centrifugation, the supernatants were dialyzed against 50 $\mathrm{mM}$ Tris- $\mathrm{HCl}(\mathrm{pH} 8.0)$ and $0.15 \mathrm{M} \mathrm{NaCl}$ at $4^{\circ} \mathrm{C}$ overnight using Slide-A-Lyzer MINI Dialysis Units (Pierce, Rockford, IL). The protein contents in the lysates were measured using a Micro BCA Protein Assay Reagent Kit (Pierce), and aliquots containing $30 \mu \mathrm{g}$ of protein were immobilized on nitrocellulose membranes (GE Healthcare, Buckinghamshire, UK) using a PR648 Slot Blot Manifold dot blot apparatus (GE Healthcare). The membranes were blocked with $10 \%$ non-fat milk, and incubated with the 6084 antibody recognizing G1 [11] or the $2 \mathrm{~B} 1$ antibody recognizing G3 [4]. In the breast cancer tissues, the staining intensities with the 6084 and 2B1 antibodies were increased by about two-fold and four-fold, respectively, compared with the non-cancerous tissues [7]. Immunohistochemical staining supported these findings.

The G1 and G3 domains are thought to be related to the proliferation and migration of cells. For example, the G1 domain stimulates cell migration and proliferation by destabilizing cell adhesion in NIH3T3 cells and astrocytoma cells [12,13]. The G3 domain promotes breast cancer cell proliferation, invasion and bone metastasis and enhances cancer apoptosis, by upregulating the epidermal growth factor receptor (EGFR)-mediating signaling pathway. Activation of phosphorylated extracellular regulated protein kinases (ERKs) is correlated with high levels of G3 expression [14]. The G3 domain contains two epidermal growth factor (EGF)-like motifs, and the activated EGF-EGFR-ERK pathway plays important roles in cell cycle progression and apoptosis.

Versican is cleaved by proteases, which play important roles in tissue remodeling and modulation of cell microenvironments through degradation of the ECM and processing of growth factors and adhesion molecules. A disintegrin and metalloproteinase with thrombospondin motifs (ADAMTS) proteins, a family of proteases, are composed of the following seven domains: signal peptide, prodomain, metalloproteinase domain, disintegrin domain, thrombospondin type 1 motif, cysteine-rich domain and spacer region. Versican is cleaved by ADAMTS-1 and ADAMTS-4 at Glu441-Ala442, and a 70-kDa neoepitope DPEAAE sequence is generated. ADAMTS-1 in breast cancer cells can promote their growth and metastasis through local accumulation of versican fragments and angiogenesis [15]. This indicates that the concentration of versican is influenced by the cleavage as well as the production, and ADAMTS plays a role in the cancer development.

\section{Hyaluronan and receptors for hyaluronan-mediated motility}

Hyaluronan (HA) is a nonsulfated glycosaminoglycan of repeating D-glucuronic acid and $\mathrm{N}$-acetyl-D-glucosamine disaccharide units. It is a major constituent of the ECM, and plays 
an important role in tissue remodeling during development $[16,17]$. The high concentrations of HA in embryonic tissues are correlated with their rates of cell migration and proliferation, and HA accumulation induces epithelial-mesenchymal transition, at regions such as the future valve sites of the embryonic heart tube. In addition, HA can bind large amounts of water, and form viscous gels at relatively low concentrations. HA is synthesized by HA synthase (HAS) enzymes at the cytoplasmic face of the plasma membrane, and its secretion takes place by extrusion during polymer elongation [18]. HAS enzymes have three different isoforms, and HAS-2 and HAS-3 are common in cancer tissues [19]. HAS-2 in breast cancer stem-like cells (CSCs) promotes tumor progression in bone by stimulating the interactions of CSCs with macrophages and stromal cells [20]. HA plays a critical role in generating a favorable microenvironment by promoting the interactions of macrophages and CSCs, and HAS-2 may promote cancer cell proliferation.

HA synthesis is correlated with the level of HAS mRNA, suggesting that transcriptional regulation is important [21]. In addition to measuring the HAS mRNA levels, several different methods have been utilized for detecting HA. Histologically, the expression of HA was evaluated by staining with biotinylated HA-binding protein $(5 \mu \mathrm{g} / \mathrm{ml})$ prepared from bovine nasal cartilage. Another method used was HA-dependent pericellular coat assays. Cells were cultured in dishes, and the medium was then replaced with phosphate-buffered saline containing $1 \times 10^{16}$ formalin-fixed horse erythrocytes. After $20 \mathrm{~min}$, the dishes were observed and areas without erythrocytes were considered to be HA [22].

HA is rich in cancer stroma, including that of lung, bladder, prostate, colon and breast cancers (Figure 3), and stromal HA accumulation is typical for high-grade and poorly differentiated carcinoma [23]. An HA rich matrix supports tumor growth and spreading by regulating cell proliferation, and migration or by enhancing tumor angiogenesis in the cancer. In breast cancer in transgenic mice, HA overproduction accelerates tumor angiogenesis through stromal reactions, most notably in the presence of versican [24]. On the other hand, the HAS suppressor, 4-methylumbelliferone (MU), suppresses cell adhesion, locomotion, and matrix metalloproteinase (MMP)-9 and N-cadherin expression, and inhibits tumor metastasis [25-27]. HA is composed of high and low molecular weight forms that have been shown to have opposite functions. High- molecular-weight HA suppresses vascularization, and has anti-inflammatory and immunosuppressive functions. Lowmolecular-weight HA, including HA oligosaccharides (less than 50 oligomers (mers)), has an angiogenic function, and induces cytokines and chemokines in inflammation and ECM degradation [28]. HA changes its biological activities depending on its molecular weight, and HA oligosaccharides (12 mers) suppress the growth of breast cancer [29]. MU and HA oligosaccharides may be candidates for anticancer therapies.

HA is present not only in the ECM, but also in the cellular cytoplasm and nucleus. Although the mechanism for HA internalization remains controversial, one possibility is that HA is transported in a retrograde manner through the Golgi, endoplasmic reticulum and cytoplasm. HA accumulation is seen in the cytoplasm of malignant cells, such as colon and gastric cancer cells and lymphoma cells. A high level of HA on tumor cells is a strong indicator of an unfavorable outcome [30]. The intracellular HA-binding proteins include 
CDC37 (p50), receptors for HA-mediated motility (RHAMM), P-32 and intracellular HAbinding protein (IHABP)-4 [31]. RHAMM was isolated from culture supernatants of chick embryonic heart fibroblasts [32], and is present in the cell membrane, centrosomes and microtubules. RHAMM is overexpressed in the G2/M phase of cancer cells and in many kinds of cancers [33,34]. These observations suggest that HA and RHAMM play important intracellular roles in mitosis, maintaining the cell shape, and modulating centrosomes and microtubules, which enhance cell proliferation and migration.

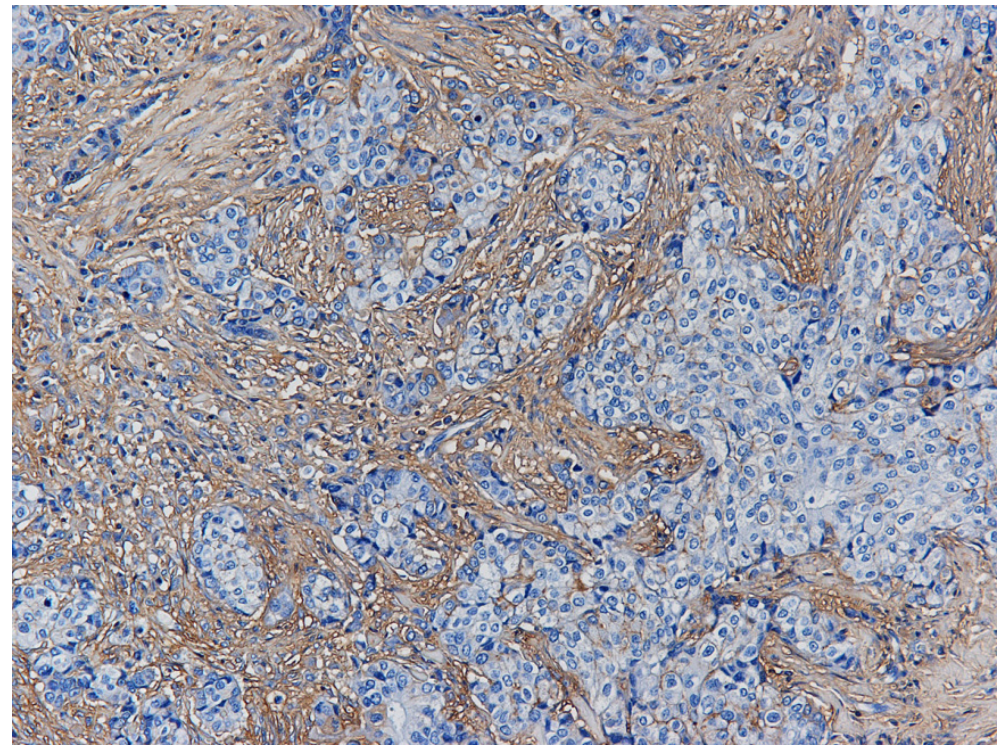

Figure 3. Histochemistry with biotinylated hyaluronan binding protein in human invasive breast cancer. Hyaluronan is expressed in cancer stroma (x200).

CDC37 and RHAMM form complexes with heat shock protein (Hsp) 90 and Hsp70, respectively [31,33]. The CDC37-Hsp90-HA complex stabilizes protein kinases such as Cdk4, p60Src kinase, casein kinase II, MPS1 kinase and Raf-1, and is important for trafficking of kinases from the cytoplasm to the nucleus. On the other hand, the complex of Hsp70 (GRP78 and GRP75) and RHAMM was confirmed by coimmunoprecipitation and glutathione-Stransferase (GST)-RHAMM fusion protein-binding assays [33]. For the GST-RHAMM fusion protein-binding assays, a membrane with transferred proteins from OHK cells (a malignant lymphoma cell line) after two-dimensional gel electrophoresis was used. The membrane was incubated with $0.05 \mu \mathrm{g} / \mathrm{ml}$ of GST-RHAMM fusion protein containing the central domain at room temperature for $1 \mathrm{~h}$. After washing with PBS/Tween-20 at room temperature for $1 \mathrm{~h}$, the localization of the RHAMM fusion protein binding was visualized using a peroxidase-conjugated anti-GST antibody (Amersham, Uppsala, Sweden) and an enhanced chemiluminescence system (Amersham). The membrane was then stripped by incubation in $0.05 \mathrm{M}$ sodium phosphate ( $\mathrm{pH}$ 6.5), $10 \mathrm{mM}$ SDS and $0.1 \mathrm{M} \beta$-mercaptoethanol at $50^{\circ} \mathrm{C}$ for $30 \mathrm{~min}$, followed by a wash with PBS/Tween-20. The stripped membrane was 
then evaluated for another GST-RHAMM fusion protein (C-terminal domain) or GST. The transferred proteins from OHK cells were visualized with Coomassie brilliant blue R-250 and the spots corresponding to the proteins bound to RHAMM were excised from the membrane and submitted for sequencing. GRP78 and GRP75 were identified as RHAMMbinding proteins [33]. Double immunostaining revealed that GRP78 and GRP75 colocalized with RHAMM in the interphase of the cell cycle. The RHAMM-Hsp70 complex may stabilize microtubules in the interphase, and the separation of RHAMM and Hsp70 may play a role in cell division.

HA is cleaved into 10 to 15 disaccharide fragments by hyaluronidases (HYALs). In humans, four HYALs have been identified, namely HYAL1, HYAL2, HYAL3 and PH20 [35]. In lung cancer, wild-type HYAL1 was associated with a poorer prognosis, while the HYAL3-v1 variant was associated with a better prognosis [36]. Increased HYAL1 expression and hyaluronidase activity are associated with an unfavorable prognosis in bladder and prostatic cancers [37].

\section{HA-versican-fibrillin-1 complex and HA-verscian complex}

Versican interacts with HA and fibrillin- 1 at its $\mathrm{N}$-terminus and $\mathrm{C}$ terminus, respectively $[2,38]$. Fibrillin-1 is a major structural component of connective tissue microfibrils, and has significant roles in the maintenance of microfibrils and elastic fibers. The HA-versicanfibrillin-1 complex and its cleavage products exist in the ciliary nonpigmented epithelium and the vitreous body [39]. Regarding skin tissues, immunoblotting analyses of skin extracts with the 6084 antibody and biotin-conjugated HA revealed that versican was a major HAbinding component in the dermis [11]. MMP-12 (macrophage metalloelastase) degraded versican and abrogated its HA-binding ability. Immunohistochemical analyses revealed that the elastic materials in solar elastosis lesions were negative for 6084 antibody, but positive for $2 \mathrm{~B} 1$ antibody, indicating loss of the HA-binding regions in the aggregated elastic fibers. In solar elastosis, which is seen in photoaged skin of elderly people, abrogation of the HAbinding ability of versican by MMP-12 is observed. On the other hand, assembly of HAversican aggregates in the pericellular sheath of cancer cells promotes their motility [40]. Similar locations of HA, versican and fibrillin-1 were seen in the ECM of breast cancer tissues [7], but their exact functions in cancer were not elucidated.

\section{Latent transforming growth factor $\beta$ binding proteins}

Latent transforming growth factor $\beta$ binding protein (LTBPs) are large extracellular glycoproteins that are structurally related to fibrillins, and are major regulators of transforming growth factor- $\beta$ (TGF- $\beta$ ) bioavailability and action [41]. TGF- $\beta$ is a potent growth inhibitor in the early stage of carcinogenesis, controlling cellular growth and inducing apoptosis. In the advanced stage of carcinogenesis, TGF- $\beta$ acts as an oncogenic factor and induces invasion-associated epithelial-mesenchymal transition. TGF- $\beta$ is thought to enhance tumor growth and invasion through regulation of immune functions and angiogenesis, as well as the production of stromal components [42]. TGF- $\beta$ is secreted as a 
latent complex containing one of the LTBPs. Latent TGF- $\beta$ consists of the mature growth factor and the TGF- $\beta$ propeptide, also known as the latency-associated peptide (LAP). The LTBPs and TGF- $\beta$ propeptides have four and three isoforms, respectively. LTBP-1 and LTBP-3 bind all three TGF- $\beta$ LAP isoforms with high affinity, while LTBP-4 shows a weak binding capacity only for the TGF- $\beta 1$ LAP isoform. LTBP-1, LTBP-3 and LTBP-4 regulate TGF- $\beta$ action at multiple levels [41]; (a) they ensure correct folding and efficient secretion; (b) they direct temporal and spatial deposition in the extracellular space; and (c) they regulate activation. These findings show that LTBPs have multiple roles with regard to TGF$\beta$ action, and the instability of the TGF- $\beta$ associations with LTBPs yields inflammation and tumors. It has been reported that LTBP-1 and LTBP-3 expression is downregulated in hepatoma and mesothelioma, respectively, compared with normal tissues $[43,44]$. In breast cancer tissues, LTBP-4 was decreased (Figure 4) [7]. Downregulation of LTBP-3 expression in malignant mesothelioma contributes to increased TGF- $\beta$ signaling activity [44], and upregulated TGF- $\beta$ signaling following LTBP reduction seems to induce carcinoma. TGF- $\beta$ signaling plays a key role in carcinogenesis, and the LTBP downregulation appears to be critical to cancer progression.

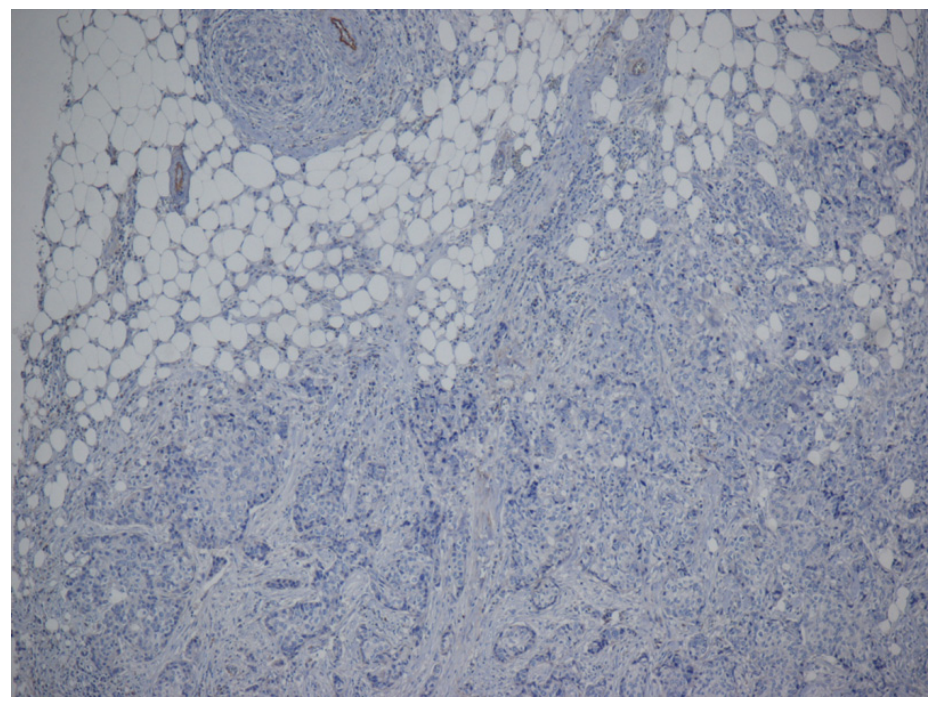

Figure 4. Anti LTBP-4 immunohistochemistry of human invasive breast cancer. LTBP-4 expression is absent (x100).

\section{Conclusion}

Versican, HA and LTBP distributions in the cancer ECM differ from those of normal tissues (Figure 5), and the ECM alteration facilitates cancer cell proliferation, migration and angiogenesis. In addition, these proteins can interact with each other, and exert a crucial role in the cancer progression. For these reasons, a novel cancer therapy that targets an individual ECM protein and the complex of these ECM proteins is proposed. One of our 
future research goals is to elucidate the function of HA-versican-microfibril complex in the cancer stroma.

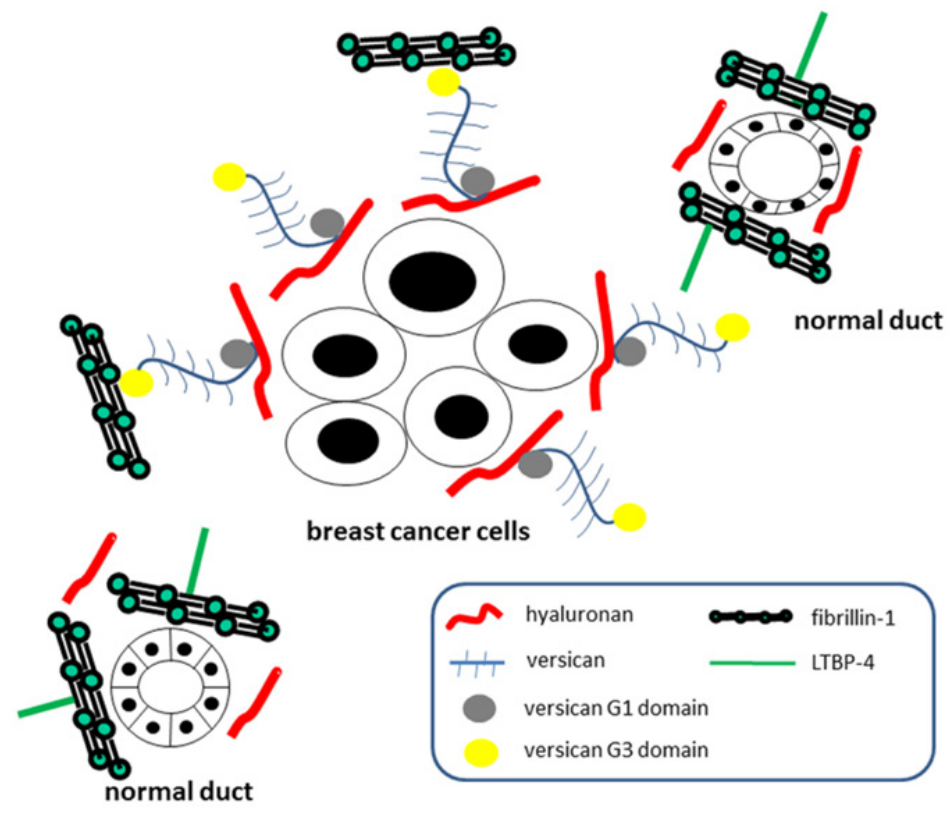

Figure 5. A diagram of the breast cancer tissue. Cancer stroma is rich in hyaluronan and versican, while normal tissues have LTBP-4.

\section{Author details}

Hiroko Kuwabara

Department of Pathology, Osaka Medical College, Japan

Masahiko Yoneda

Department of Nursing and Health, School of Nursing and Health, Aichi Prefectural University, Japan

Zenzo Isogai

Department of Advanced Medicine, National Center for Geriatrics and Gerontology, Japan

\section{References}

[1] Ma XJ, Dahiya S, Richardson E, Erlander M, Sgroi DC (2009) Gene expression profiling of the tumor microenvironment during breast cancer progression. Breast Cancer Res. 11: R7. 
[2] Kimata K, Oike Y, Tani K, Shinomura T, Yamagata M, Uritani M, Suzuki S (1986) A large chondroitin sulfate proteoglycan (PG-M) synthesized before chondrogenesis in the limb bud of chick embryo. J. Biol. Chem. 261: 13517-13525.

[3] Wight TN (2002) Versican: a versatile extracellular matrix proteoglycan in cell biology. Curr. Opin. Cell Biol. 14: 617-623.

[4] Isogai Z, Shinomura T, Yamakawa N, Takeuchi J, Tsuji T, Heinegard D, Kimata K (1996) 2B1 antigen characteristically expressed on extracellular matrices of human malignant tumors is a large chondroitin sulfate proteoglycan, PG-M/versican. Cancer Res. 56: 3902-3908.

[5] Ito K, Shinomura T, Zako M, Ujita M, Kimata K (1995) Multiple forms of mouse PG-M, a large chondroitin sulfate proteoglycan generated by alternative splicing. J. Biol. Chem. 270: 958-965.

[6] Sheng W, Wang G, Wang Y, Liang J, Wen J, Zheng PS, Wu Y, Lee V, Slingerland J, Dumont D, Yang BB (2005) The roles of versican V1 and V2 isoforms in cell proliferation and apoptosis. Mol. Biol. Cell. 16: 1330-1340.

[7] Takahashi Y, Kuwabara H, Yoneda M, Isogai Z, Tanigawa N, Shibayama Y (2012) Versican G1 and G3 domains are upregulated and latent transforming growth factor- $\beta$ binding protein-4 is downregulated in breast cancer stroma. Breast Cancer. 19: 46-53.

[8] Wasa J, Nishida Y, Shinomura T, Isogai Z, Futamura N, Urakawa H, Arai E, Kozawa E, Tsukushi S, Ishiguro N (2012) Versican V1 isoform regulates cell-associated matrix formation and cell behavior differentially from aggrecan in Swarm rat chondrosarcoma cells. Int. J. Cancer. 130: 2271-81.

[9] Serra M, Miquel L, Domenzain C, Docampo MJ, Fabra A, Wight TN, Bassols A (2005) V3 versican isoform expression alters the phenotype of melanoma cells and their tumorigenic potential. Int. J. Cancer. 114: 879-886.

[10] Miquel-Serra L, Serra M, Hernandez D, Domenzain C, Docampo MJ, Rabanal RM, de Torres I, Wight TN, Fabra A, Bassols A (2006) V3 versican isoform expression has a dual role in human melanoma tumor growth and metastasis. Lab. Invest. 86: 889-901.

[11] Hasegawa K, Yoneda M, Kuwabara H, Miyaishi O, Itano N, Ohno A, Zako M, Isogai Z (2007) Versican, a major hyaluronan-binding component in the dermis, loses its hyaluronan-binding ability in solar elastosis. J. Invest. Dermatol. 127: 1657-1663.

[12] Yang BL, Zhang Y, Cao L, Yang BB (1999) Cell adhesion and proliferation mediated through the G1 domain of versican. J. Cell Biochem. 72: 210-220.

[13] Ang LC, Zhang Y, Cao L, Yang BL, Young B, Kiani C, Lee V, Allan K, Yang BB (1999) Versican enhances locomotion of astrocytoma cells and reduces cell adhesion through its G1 domain. J. Neuropathol. Exp. Neurol. 58: 597-605.

[14] Du WW, Yang BB, Shatseva TA, Yang BL, Deng Z, Shan SW, Lee DY, Seth A, Yee AJ (2010) Versican G3 promotes mouse mammary tumor cell growth, migration, and metastasis by influencing EGF receptor signaling. Plos. One. 5: e13828.

[15] Ricciardelli C, Frewin KM, Tan IA, Williams ED, Opeskin K, Pritchard MA, Ingman WV, Russell DL (2011) The ADAMTS1 protease gene is required for mammary tumor growth and metastasis. Am. J. Pathol. 179: 3075-3085.

[16] Laurent TC, Fraser JR (1992) Hyaluronan. FASEB J 6: 2397-2404. 
[17] Fraser JR, Laurent TC, Laurent UB (1997) Hyaluronan: its nature, distribution, functions and turnover. J. Intern. Med. 242: 27-33.

[18] Weigel PH, Hascall VC, Tammi M (1997) Hyaluronan synthases. J. Biol. Chem. 272: 13997-14000.

[19] Kuwabara H, Yoneda M, Nagai M, Nishio H, Tasaka T, Suzuki K, Mori H (2003) High levels of hyaluronan production by a malignant lymphoma cell line with primary effusion lymphoma immunophenotype OHK. Br. J. Haematol. 120: 1055-1057.

[20] Okuda H, Kobayashi A, Xia B, Watabe M, Pai SK, Hirota S, Xing F, Liu W, Pandey PR, Fukuda K, Modur V, Ghosh A, Wilber A, Watabe K (2012) Hyaluronan synthase HAS2 promotes tumor progression in bone by stimulating the interaction of breast cancer stem-like cells with macrophages and stromal cells. Cancer Res. 72: 537-547.

[21] Tammi RH, Passi AG, Rilla K, Karousou E, Vigetti D, Makkonen K, Tammi MI (2011) Transcriptional and post-transcriptional regulation of hyaluronan synthesis. FEBS. J. 278: 1419-1428.

[22] Kuwabara H, Yoneda M, Nagai M, Hayasaki H, Mori H (2004) A new polyclonal antibody that recognizes a human receptor for hyaluronan mediated motility. Cancer Lett. 210: 73-80.

[23] Tammi RH, Kultti A, Kosma VM, Pirinen R, Auvinen P, Tammi MI (2008) Hyaluronan in human tumors: Pathobiological and prognostic messages from cell-associated and stromal hyaluronan. Semin. Cancer Biol. 18: 288-295.

[24] Koyama H, Hibi T, Isogai Z, Yoneda M, Fujimori M, Amano J, Kawakubo M, Kannagi R, Kimata K, Taniguchi S, Itano N (2007) Hyperproduction of hyaluronan in neuinduced mammary tumor accelerates angiogenesis through stromal cell recruitment. Possible involvement of versican/PG-M. Am. J. Pathol. 170: 1086-1099.

[25] Yoshihara S, Kon A, Kudo D, Nakazawa H, Kakizaki I, Sasaki M, Endo M, Takagaki K (2005) A hyaluronan synthase suppressor, 4-methylumbelliferone, inhibits liver metastasis of melanoma cells. FEBS. Lett. 579: 2722-2726.

[26] Kuwabara H, Yoneda M, Hayasaki H, Nakamura T, Shibayama Y (2011) A hyaluronan synthase suppressor, 4-methylumbelliferone, inhibits the tumor invasion associated with N-cadherin decreasement. Pathol. Int. 61: 262-263.

[27] Nakamura R, Kuwabara H, Yoneda M, Yoshihara S, Ishikawa T, Miura T, Nozaka H, Nanashima N, Sato T, Nakamura T (2007) Suppression of matrix metalloproteinase-9 by 4-methylumbelliferone. Cell Biol Int 31: 1022-1026.

[28] Noble PW, McKee CM, Cowman M, Shin HS (1996) Hyaluronan fragments activate an $\mathrm{NF}-\kappa \mathrm{B} / \mathrm{I}-\kappa \mathrm{B} \alpha$ autoregulatory loop in murine macrophages. J. Exp. Med. 183: 2373-2378.

[29] Misra S, Ghatak S, Zoltan-Jones A, Toole BP (2003) Regulation of multidrug resistance in cancer cells by hyaluronan. J. Biol. Chem. 278: 25285-25288.

[30] Huang L, Grammatikakis N, Yoneda M, Banerjee SD, Toole BP (2000) Molecular characterization of a novel intracellular hyaluronan-binding protein. J. Biol. Chem. 275: 29829-29839.

[31] Yoneda M (2001) Key molecules to an understanding of intracellular hyaluronan function. Connect. Tissue. 33: 227-233. 
[32] Turley EA (1982) Purification of a hyaluronan-binding protein fraction that modifies cell social behavior. Biochem. Biophys. Res. Commun. 108: 1016-1024.

[33] Kuwabara H, Yoneda M, Hayasaki H, Nakamura T, Mori H (2006) Glucose regulated proteins 78 and 75 bind to the receptor for hyaluronan mediated motility in interphase microtubules. Biochem. Biophys. Res. Commun. 339: 971-976.

[34] Ishigami S, Ueno S, Nishizono $Y$, Matsumoto $M$, Kurahara H, Arigami T, Uchikado $Y$, Setoyama T, Arima H, Kita Y, Kijima Y, Kitazono M, Natsugoe S (2011) Prognostic impact of CD168 expression in gastric cancer. BMC. Cancer. 11: 106.

[35] Stern R (2003) Devising a pathway for hyaluronan catabolism: are we there yet? Glycobiology 13: 105R-115R.

[36] de Sa VK, Olivieri E, Parra ER, Ab'Saber AM, Takagaki T, Soares FA, Carraro D, Carvalho L, Capelozzi VL (2012) Hyaluronidase splice variants are associated with histology and outcome in adenocarcinoma and squamous cell carcinoma of the lung. Hum. Pathol. 43: 675-683.

[37] Posey JT, Soloway MS, Ekici S, Sofer M, Civantos F, Duncan RC, Lokeshwar VB (2003) Evaluation of the prognostic potential of hyaluronic acid and hyaluronidase (HYAL1) for prostate cancer. Cancer Res. 63: 2638-2644.

[38] Isogai Z, Aspberg A, Keene DR, Ono RN, Reinhadt DP, Sakai LY (2002) Versican interacts with fibrillin-1 and links extracellular microfibrils to other connective tissur networks. J. Biol. Chem. 277: 4565-4572.

[39] Ohno-Jinno A, Isogai Z, Yoneda M, Kasai K, Miyaishi O, Inoue $Y$, Kataoka T, Zhao JS, Li H, Takeyama M, Keene DR, Sakai LY, Kimata K, Iwaki M, Zako M (2008) Versican and fibrillin-1 form a major hyaluronan-binding complex in the ciliary body. Invest. Ophthalmol. Vis. Sci. 49: 2870-2877.

[40] Ricciardelli C, Russell DL, Ween MP, Mayne K, Suwiwat S, Byers S, Marshall VR, Tilley WD, Horsfall DJ (2007) Formation of hyaluronan- and versican-rich pericellular matrix by prostate cancer cells promotes cell motility. J. Biol. Chem. 282: 10814-10825.

[41] Todorovic V, Rifkin DB (2012) LTBPs, more than just an escort service. J. Cell. Biochem. 113: 410-418.

[42] Imamura T, Hikita A, Inoue $Y$ (2012) The roles of TGF- $\beta$ signaling in carcinogenesis and breast cancer metastasis. Breast Cancer. 19: 118-124.

[43] Roth-Eichhorn S, Heitmann B, Flemming P, Kubicka S, Trautwein C (2001) Evidence for the decreased expression of the latent TGF- $\beta$ binding protein and its splice form in human liver tumours. Scand. J. Gastroenterol. 11: 1204-1210.

[44] Vehvilainen P, Koli K, Myllarniemi M, Lindholm P, Soini Y, Salmenkivi K, Kinnula VL, Keski-Oja J (2011) Latent TGF- $\beta$ binding proteins (LTBPs) 1 and 3 differentially regulate transforming growth factor- $\beta$ activity in malignant mesothelioma. Hum. Pathol. 42: 269278. 